\title{
Health-related quality of life in ANCA-associated vasculitis and item generation for a disease- specific patient-reported outcome measure
}

This article was published in the following Dove Press journal:

Patient Related Outcome Measures

\begin{abstract}
Joanna C Robson, ${ }^{1,2}$ jill Dawson, ${ }^{3}$
Peter F Cronholm, ${ }^{4}$ Nataliya Milman, ${ }^{5}$ Katherine S Kellom, ${ }^{6}$ Susan

Ashdown, ${ }^{7}$ Ebony Easley, ${ }^{8}$ John T Farrar, ${ }^{9}$ Don Gebhart, ${ }^{10,11}$ Georgia Lanier, ${ }^{10,11}$ Carol A McAlear, ${ }^{12}$ Jacqueline Peck, ${ }^{7}$ Raashid A Luqmani, ${ }^{7}$ Judy A Shea, ${ }^{13}$ Gunnar Tomasson, ${ }^{14}$ Peter A Merkel ${ }^{10,11}$
\end{abstract}

'Department of Rheumatology, Faculty of Health and Applied Sciences, University of the West of England, Bristol, UK; ${ }^{2}$ School of Clinical Sciences, University of Bristol, Bristol, UK; ${ }^{3}$ Department of Population Health (HSRU), University of Oxford, Oxford, UK; ${ }^{4}$ Department of Family Medicine and Community Health, University of Pennsylvania, Philadelphia, PA, USA; ${ }^{5}$ Division of Rheumatology, Department of Medicine, University of Ottawa, Ottawa Hospital Research Institute, Ottawa, ON, Canada; ${ }^{6}$ PolicyLab, Children's Hospital of Philadelphia, Philadelphia, PA, USA; ${ }^{7}$ Nuffield Department of Orthopaedics, Rheumatology and Musculoskeletal Sciences, University of Oxford, Oxford, UK; ${ }^{8}$ Department of Family Medicine and Community Health, Mixed Methods Research Laboratory, University of Pennsylvania, Philadelphia, PA, USA; ${ }^{9}$ Biostatistics and Epidemiology, Hospital of the University of Pennsylvania, Philadelphia, PA, USA; ${ }^{10}$ Division of Rheumatology, Department of Medicine, University of Pennsylvania, Philadelphia, PA, USA "Department of Biostatistics and Clinical Epidemiology, University of Pennsylvania, Philadelphia, PA, USA; ${ }^{2}$ Vasculitis Research, University of Pennsylvania, Philadelphia, PA, USA; ${ }^{13}$ School of Medicine, University of Pennsylvania, Philadelphia, PA, USA;

${ }^{14}$ Department of Public Health Sciences, University of Iceland, Reykjavik, Iceland

Correspondence: Joanna C Robson Rheumatology Unit, Bristol Royal Infirmary, Bristol, BS2 8HW, UK Tel +44 I I7 34274 I5

Email Jo.Robson@uwe.ac.uk
Objective: The antineutrophil cytoplasmic antibody (ANCA)-associated vasculitides (AAVs) are multisystem diseases of the small blood vessels. Patients experience irreversible damage and psychological effects from AAV and its treatment. An international collaboration was created to investigate the impact of AAV on health-related quality of life (HRQoL), and develop a disease-specific patient-reported outcome measure to assess outcomes of importance to patients. Methods: Patients with AAV from the UK, USA, and Canada were interviewed to identify salient aspects of HRQoL affected by AAV. The study was overseen by a steering committee including four patient research partners. Purposive sampling of interviewees ensured representation of a range of disease manifestations and demographics. Inductive analysis was used to identify themes of importance to patients; these were further confirmed by a free-listing exercise in the US. Individual themes were recast into candidate items, which were scrutinized by patients, piloted through cognitive interviews and received a linguistic and translatability evaluation.

Results: Fifty interviews, conducted to saturation, with patients from the UK, USA, and Canada, identified 55 individual themes of interest within seven broad domains: general health perceptions, impact on function, psychological perceptions, social perceptions, social contact, social role, and symptoms. Individual themes were constructed into $>100$ candidate questionnaire items, which were then reduced and refined to 35 candidate items.

Conclusion: This is the largest international qualitative analysis of HRQoL in AAV to date, and the results have underpinned the development of 35 candidate items for a disease-specific, patient-reported outcome questionnaire.

Keywords: ANCA-associated vasculitis, quality of life, patient-reported outcomes, granulomatosis with polyangiitis, microscopic polyangiitis, eosinophilic granulomatosis with polyangiitis

\section{Introduction}

Granulomatosis with polyangiitis (GPA), microscopic polyangiitis (MPA), and eosinophilic granulomatosis with polyangiitis (EGPA) are organ- and life-threatening multisystem diseases of small arteries, known as the antineutrophil cytoplasmic antibody (ANCA)-associated vasculitides (AAVs). ${ }^{1}$ Patients present with inflammation in multiple body areas, including the lungs, ear, nose, kidneys, joints, and nerves, ${ }^{2}$ with fevers, weight loss, and fatigue. ${ }^{3}$ Treatment is with glucocorticoids and other immunosuppressants. ${ }^{4} \mathrm{~A}$ third of patients will have irreversible damage at diagnosis, ${ }^{5}$ and $40 \%$ will suffer relapse. ${ }^{6}$ One-year mortality in AAV has been $>15 \%,{ }^{7}$ a poorer survival rate than breast or prostate cancer; ${ }^{8}$ however, mortality in AAV has improved, likely due to the adoption of newer treatment regimens. ${ }^{9,10}$ Surveys have demonstrated impairments in health-related quality of life (HRQoL) in AAV, in particular fatigue. ${ }^{3,11-18}$ 
A clinician-derived survey to assess patient perspectives in granulomatosis with polyangiitis was developed in $1998 ;{ }^{19}$ however, there have been no in-depth qualitative studies to capture patient perspectives on the full range of HRQoL in the AAVs as a whole.

Due to the relative rarity of AAV, with three overlapping disease phenotypes, patients with AAV are frequently considered together, ${ }^{4}$ with patients with GPA and MPA included within the same randomized controlled trials (RCTs). ${ }^{20-22}$ Primary outcomes are based on the physician-based Birmingham Vasculitis Activity Score, ${ }^{23,24}$ which records the presence or absence of disease activity. ${ }^{20-22,25}$ Patients with AAV, however, often have different perceptions of what is important to their physicians, for example, they rank fatigue as more important than dialysis or oxygen dependence. ${ }^{11}$ To guage the efficacy of treatments within RCTs, validated measurement of both physician- and patient-focused outcomes is key. ${ }^{11,26}$

The Outcome Measurement in Rheumatology (OMERACT) Vasculitis Working Group has consistently highlighted the need for a disease-specific patient-reported outcome (PRO) measure for patients with $\mathrm{AAV},{ }^{25,27}$ due to concern that the generic Medical Outcomes Short Form-36 (SF-36) may not capture all themes of importance. Since OMERACT 2012, ${ }^{27,28}$ an international collaboration (the UK, the USA, and Canada) has been developing an AAV disease-specific PRO measure, in line with the US Food and Drug Administration (FDA) guidelines for the development of PROs. ${ }^{29}$ The development of a new PRO instrument involves three distinct stages with patient involvement at each step: 1) item generation and piloting, 2) item reduction and scale generation, and 3 ) testing reliability and validity.

This paper describes the themes of importance in HRQoL in relation to $\mathrm{AAV}$, identified through in-depth qualitative analysis in three countries in order to produce candidate questionnaire items for a new disease-specific PRO for AAV.

\section{Methods}

The study steering committee included members from the UK, USA, and Canada: four patient partners; medical sociologists with extensive experience in PROM development, testing, and application; qualitative researchers; and clinical researchers with an interest in vasculitis. An initial conceptual framework was developed, through literature review and steering committee input, to explore domains of interest, and this framework evolved during the study.

A core qualitative working group (CQWG), comprising researchers from the three countries, performed the qualitative analysis, developed a collaborative code book of themes, and produced and refined candidate items. The steering committee gave critical feedback throughout on developing themes and items and the project received critical scrutiny at three successive Vasculitis Workshop sessions at Outcome Measures in Rheumatology (OMERACT) conferences. ${ }^{27,28}$

\section{Patient study sample}

Patients diagnosed with AAV were recruited from three rheumatology centers in the UK, USA, and Canada. Inclusion criteria were age $\geq 18$, ability to give informed consent, and a clinically verified diagnosis of GPA, MPA, or EGPA. Patients were purposively sampled to assure adequate representation of all three diseases, chronicity of disease, different age ranges, sex, and organ involvement. Study approvals were given by the NHS Research Committee South West-Central Bristol, the University of Pennsylvania Office of Regulatory Affairs, and the Ottawa Hospital's Research Ethics Board. All patients provided written informed consent.

\section{In-depth interviews}

Exploratory semi-structured patient interviews were conducted to identify the range of salient aspects of HRQoL affected by AAV and its treatment. An interview guide of prompts and cues was developed by the steering committee. Interviews were performed by a qualitative researcher in the US (KK) and two clinical research fellows trained in qualitative interview techniques in the UK (JCR) and Canada (NM).

\section{Analysis}

Interviews were recorded and transcribed, anonymized, and systematically analyzed using a modified framework method. ${ }^{30-32}$ Coding was carried out using both an inductive (codes emerged during analysis) and deductive (codes anticipated) approach, ${ }^{33}$ with NVivo computer software used to index transcripts. ${ }^{34}$ Interviews continued until no new substantive themes arose indicating data saturation. ${ }^{35}$ The CQWG defined the themes of interest, produced a common thematic framework, and ensured uniformity of coding across sites. A proportion of transcripts from each site was double coded, to ensure common approaches.

\section{Candidate item development}

Members of the CQWG recast themes as candidate items, using patients' descriptions throughout. Items were amended, and sometimes deleted by the CQWG, to reduce ambiguity and duplication. Piloting and further item amendment was conducted following feedback from steering committee patient partners. 
US participants were invited to participate in a free-listing activity, a semi-structured interview technique in which participants are given a question or statement and asked to identify words they associate with that phrase. ${ }^{36}$ This method uncovers how groups of people with shared experiences create, associate, and categorize topics. ${ }^{36,37}$

The following questions were asked: "Which words would you use to describe your symptoms when your vasculitis: 1) first started; 2) is under control; and 3) is starting to flare?" Patient partners on the study team performed pile-sorting of the responses independently, with disagreement resolved through consensus. Following free-listing and pile-sorting, the Smith's Salience Index (SSI) ${ }^{38,39}$ was used to identify the most salient terms. SSI scores were calculated using ARTHROPAC software. The identified salient terms were contrasted across interview themes to provide additional lens of validation for candidate item development.

\section{Patient refinement}

Three rounds of patient cognitive interviews were completed, in order to check understanding and interpretation of the candidate items ${ }^{40,41}$ This was an iterative process, with items refined or rejected by the CQWG between each round.

In parallel, a readability and translatability assessment was completed in collaboration with a specialist UK company (Pharmaquest - translation and linguistic validation company for PROs). ${ }^{42}$ A breakout session was also held at the Vasculitis Workshop at OMERACT 2014, which sought feedback about 1) inclusion of contextual factors within the PRO and 2) attribution within the stem (or lead in sentence), to vasculitis and/or its treatment. All proposed item changes were tested by further cognitive interviews and steering committee review.

\section{Results}

Fifty participants, 24 men and 26 women, were interviewed in the UK, USA, and Canada. Participants' characteristics are shown in Table 1. Interview transcripts were analyzed, identifying 55 individual themes of interest, grouped into seven domains (definitions of individual themes within the codebook in Table S1). The domains identified were general health perceptions, impact on function, psychological perceptions, social perceptions, social contact, social roles, and symptoms (Box 1 shows domain structure and individual themes). The saturation table of emergent themes is shown in Table S2.

\section{General health perceptions}

Eighty-six percent of patients used descriptions of how their general sense of self and wellness had been affected by developing AAV. Concerns about the future and difficulties making long-term plans were prominent, as was a sense of vulnerability in one's own body.

Table I Demographic and disease features of 50 patients with ANCA-associated vasculitis

\begin{tabular}{|c|c|c|c|c|}
\hline Demographics & $\begin{array}{l}\text { Oxford, } \\
\text { UK }(n=18)\end{array}$ & $\begin{array}{l}\text { Philadelphia, } \\
\text { PA, USA }(n=17)\end{array}$ & $\begin{array}{l}\text { Ottawa, ONT, } \\
\text { Canada }(n=15)\end{array}$ & $\begin{array}{l}\text { Total patients } \\
(n=50)\end{array}$ \\
\hline \multicolumn{5}{|l|}{ Sex, n (\%) } \\
\hline Male & $12(66.7)$ & $6(35.3)$ & $6(40.0)$ & $24(48.0)$ \\
\hline Female & $6(33.3)$ & II (64.7) & $9(60.0)$ & $26(52.0)$ \\
\hline \multicolumn{5}{|l|}{ Age, n (\%) } \\
\hline$<50$ years & $3(16.7)$ & $5(29.4)$ & $2(13.3)$ & $10(20.0)$ \\
\hline$\geq 50$ years & $15(83.3)$ & $12(70.6)$ & I3 (86.7) & $40(80.0)$ \\
\hline \multicolumn{5}{|l|}{ Diagnosis, n (\%) } \\
\hline GPA & $8(44.4)$ & $9(52.9)$ & $8(53.3)$ & $25(50.0)$ \\
\hline MPA & $3(16.7)$ & $3(17.7)$ & I (6.67) & $7(14.0)$ \\
\hline EGPA & 7 (38.9) & $5(29.4)$ & $6(40.0)$ & $18(36)$ \\
\hline \multicolumn{5}{|c|}{ Time from diagnosis, $\mathbf{n}(\%)$} \\
\hline$<2$ years & $13(72.2)$ & I $6(94.1)$ & $5(33.3)$ & $34(68)$ \\
\hline$\geq 2$ years & $5(27.8)$ & I (5.88) & $10(66.7)$ & $16(32)$ \\
\hline \multicolumn{5}{|c|}{ Flare <2 years, $\mathrm{n}(\%)$} \\
\hline Yes & $6(33.3)$ & $16(94.1)$ & $4(26.7)$ & $26(52.0)$ \\
\hline No & $12(66.7)$ & I (5.88) & II (73.3) & $24(48.0)$ \\
\hline \multicolumn{5}{|c|}{ Organ involvement, n (\%) } \\
\hline Kidney & $9(50)$ & $5(29.4)$ & $2(13.3)$ & $16(32.0)$ \\
\hline Lung & $12(66.7)$ & $10(58.8)$ & $12(80)$ & $34(68.0)$ \\
\hline ENT & $10(55.6)$ & II (64.7) & $14(93.3)$ & $35(70)$ \\
\hline Neurological & $4(22.2)$ & $6(35.3)$ & I (6.67) & $12(24)$ \\
\hline
\end{tabular}

Abbreviations: ANCA, antineutrophil cytoplasmic antibody; EGPA, eosinophilic granulomatosis with polyangiitis; ENT, ear nose and throat; GPA, granulomatosis with polyangiitis; MPA, microscopic polyangiitis. 
Box I Domains and individual themes from patients with ANCA-associated vasculitis

\begin{tabular}{|c|c|c|}
\hline $\begin{array}{l}\text { Domains and individual themes of int } \\
\text { emerged) }\end{array}$ & st in ANCA-associated vasculitis, $n=$ & umber of interviews from which the theme \\
\hline I. General health perceptions & 3. Psychological perceptions & 6. Social role \\
\hline a. General sense of self and wellness (43) & a. Uncertainty/concerns about future (43) & a. Occupation or finances (4I) \\
\hline b. Lack of confidence in one's body (27) & b. Fear, anxiety, stress (37) & b. Family and family planning (35) \\
\hline c. Poor response to treatment (25) & c. AAV dominates (33) & c. Dependency on others (34) \\
\hline d. Vulnerability to infection or illness (22) & d. Self-efficacy (33) & d. Role identity and status (25) \\
\hline & e. Information and knowledge (32) & \\
\hline 2. Impact on function & f. Support (29) & 7. Symptoms \\
\hline a. Level of physical function (45) & g. Depression, low mood (25) & a. Fatigue (44) \\
\hline b. Personal mobility (4I) & h. Anger and irritation (23) & b. Cognition and poor concentration (9) \\
\hline c. Scope for travel (38) & & c. Issues related to body weight (37) \\
\hline d. Household tasks (36) & 4. Social perceptions & d. Sleep symptoms (27) \\
\hline e. Treatment consumes time/focus (33) & a. Visibility of condition or side effects (34) & e. Temperature instability (II) \\
\hline f. Adaptation (necessary) (27) & b. Empathy and emotional connections (33) & f. Skin and nail problems (25) \\
\hline g. Hobbies and interests (23) & c. Source of other people's worry (30) & g. Earache and hearing difficulties (19) \\
\hline h. Use of everyday transport (I7) & & h. Upper respiratory tract (35) \\
\hline i. Eating and drinking (16) & 5. Social contact & i. Eye symptoms and affected sight (22) \\
\hline j. Everyday technology (10) & a. Impact on social life (40) & j. Cardiorespiratory symptoms (38) \\
\hline k. Washing self $(10)$ & b. Social activities and participation (3I) & k. Gastrointestinal symptoms (I8) \\
\hline I. Dressing and undressing (9) & c. Adaptations to facilitate social life (26) & I. Muscle symptoms (I6) \\
\hline & d. Quality of communication (I4) & m. Numbness and nerve symptoms (I2) \\
\hline & e. Sex and intimate relationships (7) & n. Joint symptoms (3I) \\
\hline & & o. Kidney and urinary tract (I3) \\
\hline & & p. Appetite (14) \\
\hline & & q. Sense of taste (3) \\
\hline & & r. Feeling unsteady or faint (I3) \\
\hline & & $\begin{array}{l}\text { s. Pain: pain unspecified (13), pain in feet and legs } \\
\text { (23), pain in arms and hands (19), facial and head } \\
\text { pain (18) }\end{array}$ \\
\hline
\end{tabular}

Abbreviation: ANCA, antineutrophil cytoplasmic antibody.

"If I compare to 3 years ago... I was the guy who was working 7 days a week, 16 hour days, never tired. Now... Ufff. It's not the same guy anymore." [47-year-old male with EGPA]

"I didn't want to set foot outside the door. Simply because I thought ... I can't trust my body anymore". [53-year-old female with EGPA]

\section{Impact on function}

Ninety percent of participants described difficulties with reduced levels of physical function, over $80 \%$ had a reduction in mobility, and $20 \%$ described difficulties in washing and dressing. These impairments led to frustration and impacted finances and work (82\%), the ability to perform household tasks (72\%), taking part in hobbies and interests (46\%), and restricted travel $(76 \%)$.

"Weakness, inability to walk, to use my arms, to bathe, to do anything - I just laid in bed". [82-year-old male with MPA]

"TV was a no-no. I got a telephone with a light on it, because it [the deafness] was that bad... I felt very isolated and very stupid". [57-year-old male with GPA]

\section{Psychological}

Concerns about the future were highlighted in $86 \%$ of interviews with over $70 \%$ reporting experiencing fear, anxiety, or stress, and $50 \%$ describing depression or low mood. Anger or irritation was reported by almost 50\%. Difficulties in making plans and the potential for premature death were described by patients of all ages.

"For the first year after I was diagnosed, I did nothing, apart from cope with me, my illness and trying to live as normal a life as possible". [67-year-old female with GPA]

"I was only [age], my first year of college - everything is falling apart and I think I'm dying". [36-year-old female with GPA]

\section{Social perceptions}

Participants were aware of the visibility of the condition, and its treatment side-effects, particularly in relation to glucocorticoids; these issues were discussed in $64 \%$ of interviews. A lack of empathy from others was reported by around $60 \%$ of interviewees, as was being the source of worry to others. 
“To have a big puffy moon face [due to glucocorticoids] is really hard for me. Well, you're not attractive anymore - it's weird". [33-year-old female with GPA]

"I think some people were more supportive than others, and it wasn't always the people I expected to be". [67-yearold female with GPA]

\section{Social contact}

Eighty percent of interviewees described an impact on their social life, because of fatigue, difficulties with joining in physical activities or communicating, or concerns about letting people down by having to break plans.

"If we had a dinner date on the weekend I had to rest coming up to that day just to be able to have enough energy. I got to a point where I just didn't bother". [51-year-old female with EGPA]

"Meetings were the worst. Because I found that I was lip-reading. In an open room with a number of people, it was a nightmare". [57-year-old male with GPA]

\section{Social role}

Eighty-two percent of participants discussed their occupation or finances, specifically stemming from difficulties with concentration and fatigue. Roles beyond work were also discussed, within the family (70\%), and changes to role and status when having to rely on others for help (64\%).

"When I was getting sick in the beginning I gave up my position as the executive director of the organization and I moved into a position with less responsibility". [52-year-old female with GPA]

"It was hard on my son as well, so he started goofing off in school. I felt like I wasn't a good mom, I wasn't a good wife, and I was isolated". [51-year old female with EGPA]

\section{Symptoms}

All of the patients described symptoms due to disease and treatment in depth. Nineteen different sets of symptoms were identified, most frequently fatigue (88\%), cardiorespiratory symptoms (76\%), issues related to body weight (74\%), and upper respiratory tract symptoms (70\%). A full list of symptoms is given in Box 1, with quotes in Box 2.

\section{Free-listing and pile-sorting items of importance to patients with AAV}

All 17 US patients interviewed were invited to free-list terms they associated with the onset, remission, and flaring of their AAV (Figure 1). The most salient themes at onset were pain and discomfort (SSI=0.37), nasal and sinus problems
(SSI=0.32), and fatigue and energy levels ( $\mathrm{SSI}=0.27)$. Emotional effects were within the top three during flare ( $\mathrm{SSI}=0.28$ ) and remission ( $\mathrm{SSI}=0.27)$. Themes identified were compared with the individual themes of interest and domains from the in-depth patient interviews and no new themes were identified (Box 1 for overview and Table S1 for detailed descriptions).

\section{Candidate item development}

Fifty-five individual themes were identified from the qualitative work (Box 1), and these were recast into an initial list of 105 candidate items by members of the CQWG. Patient descriptions informed the design of the candidate questionnaire items and response options, resulting in different sections. Patients described the overall severity of their symptoms, rather than the frequency; pain was usually described in relation to specific body areas, such as joints or muscles; and ability to function was described in terms of the amount of difficulty with completing a specific task. The candidate items were scrutinized for duplication and ambiguity of items, reducing the item pool to 42 items. Patients made it clear that it was difficult to tease apart symptoms caused by AAV versus its treatment, so both were included within the stem of the question. Items related to contextual factors (eg, support and self-efficacy - Box 1 and Table S1) were not included within the PRO itself, after discussion at an OMERACT 2014 breakout session with patient participants. ${ }^{28}$

Three rounds of cognitive interviews were conducted in the UK and USA, using the 42-item version of the questionnaire, with amendments after each round. Word changes were suggested by patients, for example, clarification of the word essential in relation to activities, and change to the period of recall from 7 days to 4 weeks. All participants reported that the questionnaire captured content relevant to them. Seven items were rejected because of ambiguity, repetition, or being contextual factors. Following the translatability assessment (Box S1), minor changes were made to a few items, and these revisions were piloted in the last round of interviews. The conceptual framework evolved in response to insights from the qualitative research, feedback from the steering committee, and breakout sessions at OMERACT, and the final version is shown in Figure 2. The resulting 35-item candidate pool is shown in Box 3.

\section{Discussion}

This is the most comprehensive evaluation of the patient perspective in AAV to date. Patients have been an integral part of this work as key members of the steering committee and qualitative interview participants, reflecting all three diseases, 
Box 2 Patient descriptions of symptoms of ANCA-associated vasculitis and its treatment

Fatigue: "So with the severe flares, the fatigue is indescribable. Looking back, I don't know how I got up and went to work every day last year". [30-year-old. F, GPA]

Cognition/concentration: "You feel like you have the flu, sort of achy and really tired, your head is kind of fuzzy, it's hard to think and concentrate". [52-year-old. F, GPA]

Issues related to body weight: "Taking too many prednisolone really made me eat a lot and gain weight". 58-year-old. M, EGPA.

Sleep symptoms: "I wake up tired, just really tired. There doesn't seem to be any refreshing sleep, no matter how long I try and sleep for". [53-year-old. F, EGPA]

Temperature instability: "l'd have high fevers and night sweats, tremendous night sweats". 51 -year-old. F, EGPA.

Skin problems: "Your skin is so thin that it tears" 04.202. "I had a rash, and I couldn't get rid of it, breaking out down my arms and chest... it drove me crazy". [68-year-old. F, EGPA]

Earache/hearing difficulties/upper respiratory tract: "I'm coughing up blood and I've got bloody noses. I can't hear on the phone. I've lost my hearing". [36-year-old. F, GPA]

Eye symptoms and affected sight: "It was very, very red, very painful like in the back of my eye, it was very painful, and I was sensitive to light, I couldn't read". [6I-year-old. F, GPA]

Cardiorespiratory symptoms: "I could barely walk a few yards down the road without having to stop and really catch my breath". [48-year-old. F, GPA]

Gastrointestinal symptoms: "I had been starting to get a lot of side effects from the prednisone it was really causing havoc in my digestive system". [52-year-old. F, GPA]

Muscle symptoms: “...I just don't have the muscle power in my legs. And also my arms... its worse when l'm on the steroids". [53-year-old. F, EGPA]

Nerve symptoms: "I couldn't walk, the sheer agony of the pain was bad as well, I couldn't use the hand, it went tingly and dropped, the same as the foot". [67-year-old. F, EGPA]

Joint symptoms: "I started having "rotating joint pain". It would be mostly in my legs, but sometimes in my wrists, in my elbow, but especially in my legs". [64-year-old. M, GPA]

Kidney and urinary tract: "They discovered that there was something wrong with my kidneys which was really quite a shock". [68-year-old. F, MPA]

Appetite: "And then I lost a lot of weight, I lost a stone and a half in weight even though I was trying to eat but I hadn't got a lot of appetite". [67-year-old. F, EGPA]

Feeling unsteady or faint: "I would take my bath or my shower but my husband would insist that I do it when he was there because I would feel faint". [5I-year-old. F, EGPA]

Pain: "And then the joint pains started. And that's when it became, you know, quite an issue. You know, so I had a real, real problem with pain". [66-year-old. M, GPA]

Abbreviations: ANCA, antineutrophil cytoplasmic antibody; F, female; GPA, granulomatosis with polyangiitis; EGPA, eosinophilic granulomatosis with polyangiitis; M, male; MPA, microscopic polyangiitis.

differing disease manifestations, a wide demographic range, and three different countries. The item generation for a novel, disease-specific $\mathrm{PRO}$ measure is underpinned by this qualitative research, which should ensure that the final candidate items have good face validity within each country. Themes identified in previous quantitative studies are confirmed, for example, fatigue, ${ }^{13}$ anxiety, and depression, ${ }^{16}$ and the impact on everyday function and employment. ${ }^{17,43}$ Newer themes include difficulties in making plans, from short-term social engagements to life planning, previously reported in patients with systemic lupus erythematosus, rheumatoid arthritis, and GPA. .9,44,45 $^{-10}$

The strengths of this study include a high level of patient involvement, and ongoing critical review through OMERACT Workshops, which have helped to ensure that each stage was consistent with best practice. Patients were purposively sampled to include a range of disease features and demographics, including a high proportion of patients with recent active disease. This was to ensure a focus on themes (and then items), which would exhibit greatest change in the context of a RCT. A third of patients had longer-standing disease, and saturation of themes was also reached within this patient group. The high rate of relapsing disease may also be a reflection of the fact that patients with GPA, who have a higher rate of relapse, ${ }^{46}$ were slightly over-represented compared with patients with MPA; this may be a potential bias of the sample. That only English-speaking participants were included is a limitation of this study. However, a translatability assessment was performed for the questionnaire items, to ensure that any future translation into a range of languages should be straightforward. ${ }^{47}$ In addition, care was taken to develop items that were not overly culture-specific, for example, describing "difficulties with traveling far from home," rather than "going on holidays." Interviews were performed by clinical fellows in the UK and Canada, and this may have changed the way that patients described problems in relation to their disease or treatment. Training was, therefore, 

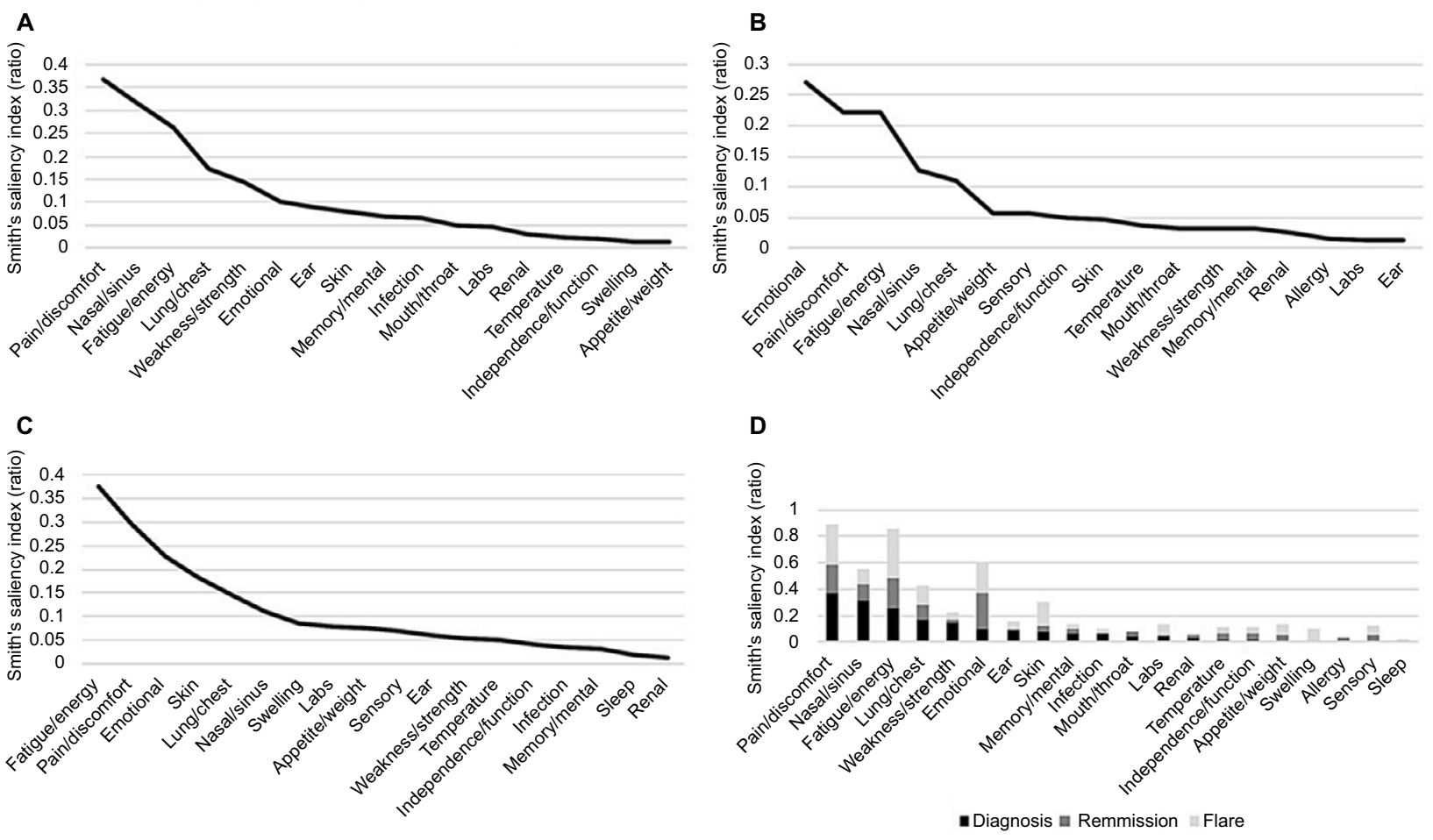

Figure I Smith's Salience Indices of patient's free-listed and ranked terms.

Notes: (A) Terms at AAV diagnosis; (B) terms during AAV remission; (C) terms during AAV flare; (D) comparison across AAV activity states.

Abbreviations: AAV, associated vasculitis; labs, laboratory tests.

Conceptual framework for the AAV-PRO

Disease context: diagnosis, flare, remission

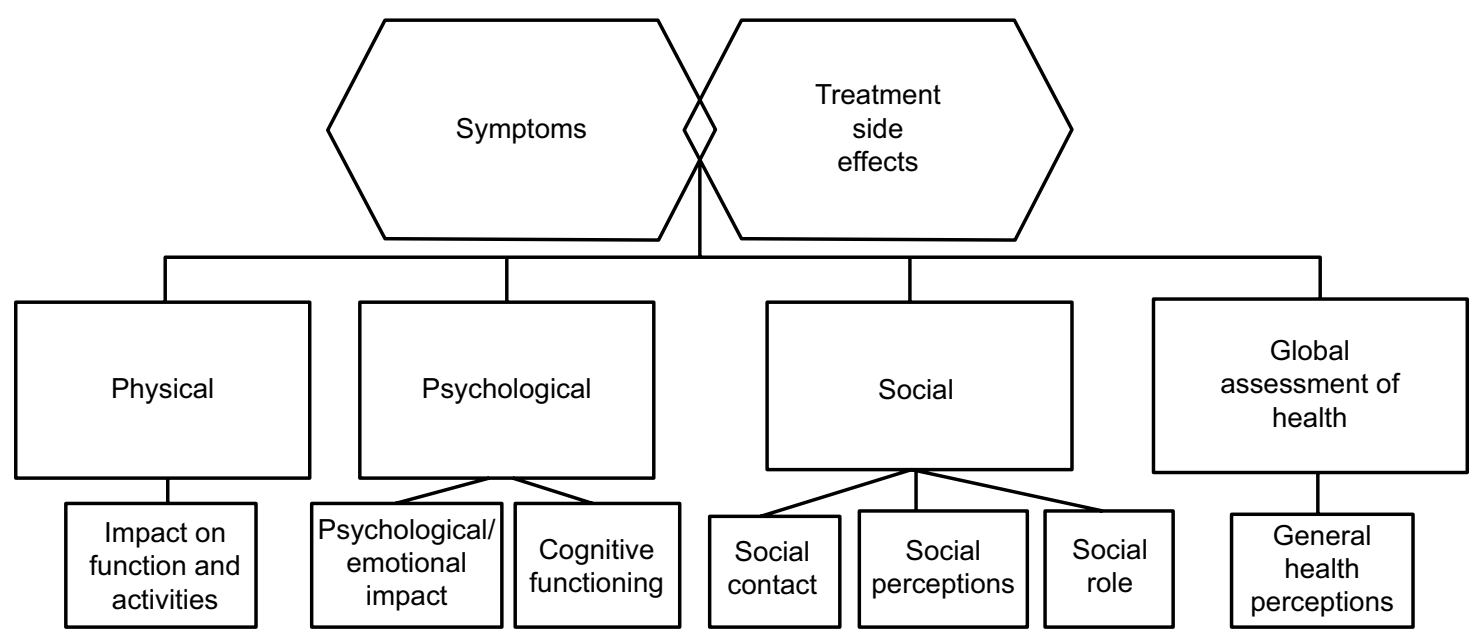

Figure 2 Conceptual framework for the AAV-PRO.

Notes: The scope of the developing measure was defined by the steering committee and evolved during development to include symptom severity, the impact of problems and limitations imposed by patients' ANCA-associated vasculitis and treatment on their work and domestic roles, family and social interactions (including activities and interests outside the home), and psychological state.

Abbreviations: AAV, ANCA-associated vasculitis; ANCA, antineutrophil cytoplasmic antibody; PRO, patient-reported outcome. 
Box 3 Candidate item pool for the questionnaire

\begin{tabular}{|c|c|}
\hline \multicolumn{2}{|r|}{$\begin{array}{l}\text {...please rate your experience of the following problems, in } \\
\text { general, during the past } 4 \text { weeks. } \\
\text { Candidate items (....abridged wording) }\end{array}$} \\
\hline 1 & Chest problems .... \\
\hline 2 & Problems with your ears.... \\
\hline 3 & Problems with your eyes .... \\
\hline 4 & Problems with your nose or .... \\
\hline 5 & Problems with your mouth or .... \\
\hline 6 & Problems with your joints.... \\
\hline 7 & ...Cramps or weakness affecting your muscles.... \\
\hline 8 & Nerve pain or numbness .... \\
\hline 9 & Problems with your skin .... \\
\hline 10 & Tiredness or fatigue.... \\
\hline 11 & Feeling uncomfortably hot, cold, or .... \\
\hline 12 & Indigestion, heartburn, nausea, or .... \\
\hline \multicolumn{2}{|r|}{$\begin{array}{l}\text {...how difficult have you found the following activities, in } \\
\text { general, during the past } 4 \text { weeks? }\end{array}$} \\
\hline 13 & Walking around .... \\
\hline 14 & Walking up ..... \\
\hline 15 & Doing physical activities .... \\
\hline 16 & Doing activities .... \\
\hline 17 & Using your hands to do ...... \\
\hline 18 & Washing and drying yourself..... \\
\hline 19 & Getting enough good sleep \\
\hline 20 & Sexual activity .... \\
\hline \multicolumn{2}{|r|}{$\begin{array}{l}\text {...how often have the following applied to you, in general, } \\
\text { during the past } 4 \text { weeks }\end{array}$} \\
\hline 21 & Concerned about weight..... \\
\hline 22 & ....Upset or frustrated \\
\hline 23 & ....Worried about the future \\
\hline \multicolumn{2}{|r|}{$\begin{array}{l}\text {...how often have the following applied to you, in general, } \\
\text { during the past } 4 \text { weeks? }\end{array}$} \\
\hline 24 & ....Worried or stressed \\
\hline 25 & ....Difficulty concentrating \\
\hline 26 & ....Down or depressed \\
\hline 27 & ....Dependent on other people \\
\hline 28 & ....Current or future income \\
\hline 29 & ....Long-term plans \\
\hline 30 & ....Social life is limited \\
\hline 31 & ....Traveling a long distance from home \\
\hline 32 & ....Embarrassed or self-conscious because of appearance ..... \\
\hline 33 & ....Let other people down \\
\hline 34 & ....Life is now focused on coping \\
\hline 35 & ....Long-term effects of treatment \\
\hline
\end{tabular}

Notes: Abridged wording given (....); survey to determine scale structure and measurement properties needed to determine final PRO items.

Abbreviation: PRO, patient-reported outcome.

provided by experienced social scientists, who also evaluated all interview transcripts.

The OMERACT Vasculitis Working Group has highlighted the lack of a disease-specific PRO for $\mathrm{AAV}^{27} \mathrm{As}$ per FDA guidance, the development of a PRO instrument should start with qualitative analysis involving patients with the disease, in order to identify themes of importance. However, generic PRO instruments, such as the SF- $36,{ }^{48}$ can be used to measure and compare HRQoL between patients with different chronic conditions, and population norms. A combined approach of using disease-specific and generic PRO measures may, therefore, be the optimum way of comprehensively measuring HRQoL in $\mathrm{AAV}^{49}$

The 35-item candidate questionnaire will need to be shortened to reduce responder burden and optimize feasibility within RCTs. The next stage of development will involve a large-scale survey to facilitate further item reduction, and determine the underlying scale structure and measurement properties (reliability, validity, and responsiveness) of the final AAV-PRO instrument.

\section{Acknowledgments}

Sponsored by the University of Oxford, the Vasculitis Clinical Research Consortium and the University of Ottawa. With support from the Medical Research Fund, Oxford, the Oxfordshire Health Services Research Committee (Ref 1098), the US National Institute of Arthritis and Musculoskeletal and Skin Diseases (U54 AR057319 and U01 AR51874), the National Center for Research Resources (U54 RR019497), and the Office of Rare Diseases Research. Oxford University Innovation funded the translatability exercise. Additional support received by a Patient-Centred Outcomes Research Institute Pilot Project Grant.

\section{Disclosure}

Dr Robson and Professor Luqmani were supported in part by the National Institute for Health Research Musculoskeletal Biomedical Research Unit, Oxford, UK. Dr Robson was supported by a National Institute for Health Research (NIHR) clinical lectureship. Dr Milman was supported by a UCB/ Canadian Rheumatology Association/Arthritis Society postgraduate rheumatology fellowship award and a research fellowship from the Department of Medicine at the Ottawa Hospital. The authors report no other conflicts of interest in this work.

\section{References}

1. Jennette JC, Falk RJ, Bacon PA, et al. 2012 revised international chapel hill consensus conference nomenclature of vasculitides. Arthritis Rheum. 2013;65(1):1-11.

2. McNicholas BA, Griffin TP, Donnellan S, et al. ANCA-associated vasculitis: a comparison of cases presenting to nephrology and rheumatology services. QJM. 2016;109(12):803-809.

3. Basu N, Jones GT, Fluck N, et al. Fatigue: a principal contributor to impaired quality of life in ANCA-associated vasculitis. Rheumatology (Oxford). 2010;49(7):1383-1390.

4. Yates M, Watts RA, Bajema IM, et al. EULAR/ERA-EDTA recommendations for the management of ANCA-associated vasculitis. Ann Rheum Dis. 2016;75(9):1583-1594.

5. Robson J, Doll H, Suppiah R, et al. Damage in the anca-associated vasculitides: long-term data from the European vasculitis study group (EUVAS) therapeutic trials. Ann Rheum Dis. 2015;74(1):177-184. 
6. Walsh M, Flossmann O, Berden A, et al. Risk factors for relapse of antineutrophil cytoplasmic antibody-associated vasculitis. Arthritis Rheum. 2012;64(2):542-548.

7. Flossmann O, Berden A, de Groot K, et al; European Vasculitis Study Group. Long-term patient survival in ANCA-associated vasculitis. Ann Rheum Dis. 2011;70(3):488-494.

8. Quaresma M, Coleman MP, Rachet B. 40-year trends in an index of survival for all cancers combined and survival adjusted for age and sex for each cancer in England and Wales, 1971-2011: a population-based study. Lancet. 2015;385(9974):1206-1218.

9. Hilhorst M, Wilde B, van Paassen P, Winkens B, van Breda Vriesman P, Cohen Tervaert JW; Limburg Renal Registry. Improved outcome in anti-neutrophil cytoplasmic antibody (ANCA)-associated glomerulonephritis: a 30-year follow-up study. Nephrol Dial Transplant. 2013;28(2):373-379.

10. Rhee RL, Hogan SL, Poulton CJ, et al. Trends in long-term outcomes among patients with ANCA-associated vasculitis with renal disease. Arthritis Rheumatol. 2016;68(7):1711-1720.

11. Herlyn K, Hellmich B, Seo P, Merkel PA. Patient-reported outcome assessment in vasculitis may provide important data and a unique perspective. Arthritis Care Res (Hoboken). 2010;62(11): 1639-1645.

12. Walsh M, Mukhtyar C, Mahr A, et al. Health-related quality of life in patients with newly diagnosed antineutrophil cytoplasmic antibody-associated vasculitis. Arthritis Care Res (Hoboken). 2011;63(7):1055-1061.

13. Basu N, McClean A, Harper L, et al. The characterisation and determinants of quality of life in ANCA associated vasculitis. Ann Rheum Dis. 2014;73(1):207-211.

14. Carpenter DM, Thorpe CT, Lewis M, Devellis RF, Hogan SL. Healthrelated quality of life for patients with vasculitis and their spouses. Arthritis Rheum. 2009;61(2):259-265.

15. Tomasson G, Boers M, Walsh M, et al. Assessment of health-related quality of life as an outcome measure in granulomatosis with polyangiitis (Wegener's). Arthritis Care Res. 2012;64(2):273-279.

16. Koutantji M, Harrold E, Lane SE, Pearce S, Watts RA, Scott DG. Investigation of quality of life, mood, pain, disability, and disease status in primary systemic vasculitis. Arthritis Rheum. 2003;49(6) 826-837.

17. Benarous L, Terrier B, Laborde-Casterot H, et al; French Vasculitis Study Group (FVSG). Employment, work disability and quality of life in patients with ANCA-associated vasculitides. The EXPOVAS study. Clin Exp Rheumatol. 2017;103(1):40-46.

18. Boomsma MM, Bij1 M, Stegeman CA, Kallenberg CG, Hoffman GS, Tervaert JW. Patients' perceptions of the effects of systemic lupus erythematosus on health, function, income, and interpersonal relationships: a comparison with Wegener's granulomatosis. Arthritis Rheum. 2002;47(2):196-201.

19. Hoffman GS, Drucker Y, Cotch MF, Locker GA, Easley K, Kwoh K. Wegener's granulomatosis: patient-reported effects of disease on health, function, and income. Arthritis Rheum. 1998;41(12):2257-2262.

20. Jones RB, Tervaert JW, Hauser T, et al; European Vasculitis Study Group. Rituximab versus cyclophosphamide in ANCA-associated renal vasculitis. N Engl J Med. 2010;363(3):211-220.

21. Stone JH, Merkel PA, Spiera R, et al; RAVE-ITN Research Group. Rituximab versus cyclophosphamide for ANCA-associated vasculitis. N Engl J Med. 2010;363(3):221-232.

22. Guillevin L, Pagnoux C, Karras A, et al; French Vasculitis Study Group. Rituximab versus azathioprine for maintenance in ANCA-associated vasculitis. N Engl J Med. 2014;371(19):1771-1780.

23. Luqmani RA, Bacon PA, Moots RJ, et al. Birmingham vasculitis activity score (BVAS) in systemic necrotizing vasculitis. QJM. 1994;87(11):671-678.

24. Mukhtyar C, Lee R, Brown D, et al. Modification and validation of the birmingham vasculitis activity score (version 3). Ann Rheum Dis. 2009;68(12):1827-1832.
25. Merkel PA, Aydin SZ, Boers M, et al. The OMERACT core set of outcome measures for use in clinical trials of ANCA-associated vasculitis. J Rheumatol. 2011;38(7):1480-1486.

26. Kirwan JR, Hewlett SE, Heiberg T, et al. Incorporating the patient perspective into outcome assessment in rheumatoid arthritis progress at OMERACT 7. J Rheumatol. 2005;32(11):2250-2256.

27. Merkel PA, Aydin SZ, Boers M, et al. Current status of outcome measure development in vasculitis. J Rheumatol. 2014;41(3):593-598.

28. Robson JC, Milman N, Tomasson G, et al. Exploration, development, and validation of patient-reported outcomes in antineutrophil cytoplasmic antibody-associated vasculitis using the OMERACT process. J Rheumatol. 2015; 42(11):2204-2209.

29. Guidance for Industry: Patient-Reported Outcome Measures: Use in Medical Product Development to Support Labelling Calims. In: (FDA) USDoHaHSFaDA, editors. Maryland: FDA; 2009.

30. McColl E. Developing questionnaires. In: Fayers P, Hays R, eds. Assessing Quality of Life in Clinical Trials. 2nd ed. Oxford, UK: Oxford Medical Publications; 2005.

31. Ritchie J, Spencer L. Qualitative data analysis for applied policy research. In: Bryman A, Burgess RG, eds. Analysing Qualitative Data. London, UK: Routledge; 1994.

32. Pope C, Ziebland S, Mays N. Qualitative research in health care. Analysing qualitative data. BMJ. 2000;320(7227):114-116.

33. Fereday J, Muir-Cochrane E. Demonstrating rigor using thematic analysis: a hybrid approach of inductive and deductive coding and theme development. Int J Qual Meth. 2006;5:1-22.

34. International Q. NVivo qualitative data analysis software. Version 10. QSR International; 2012. Available from: qsrinternational.com. Accessed October 11, 2017.

35. Kerr C, Nixon A, Wild D. Assessing and demonstrating data saturation in qualitative inquiry supporting patient-reported outcomes research. Expert Rev Pharmacoecon Outcomes Res. 2010;10(3):269-281.

36. Borgatti SP. Elicitation techniques for cultural domain analysis. Enhanced ethnographic methods: audiovisual techniques, focused group interviews, and elicitation techniques. In: Ethnographer Toolkit. Walnut Creek, CA: Alta Mira; 1999:115-151.

37. Schrauf RW, Sanchez J. Using freelisting to identify, assess, and characterize age differences in shared cultural domains. J Gerontol B Psychol Sci Soc Sci. 2008;63(6):S385-S393.

38. Borgatti SP, Carboni I. On measuring individual knowledge in organizations. Organ Res Methods. 2007;10(3):449-462.

39. Handweker WP, Borgatti SP. Reasoning with numbers. In: Bernard HR, editors. The Handbook of Methods in Cultural Anthropology. Lanham, MD: Altamira Press; 1998:549-593.

40. Drennan J. Cognitive interviewing: verbal data in the design and pretesting of questionnaires. J Adv Nurs. 2003;42(1):57-63.

41. Conrad F, Blair J. From impressions to data: increasing the objectivity of congitive interviews. Paper presented at: American Statistical Association 1996; Alexandria, VA, USA.

42. PharmaQuest [homepage]. Available at: http://www.corptransinc.com/ pharmaquest. Accessed January 5, 2017.

43. Basu N, McClean A, Harper L, et al. Markers for work disability in anti-neutrophil cytoplasmic antibody-associated vasculitis. Rheumatology (Oxford). 2014;53(5):953-956.

44. Cleanthous S, Newman SP, Shipley M, Isenberg DA, Cano SJ. What constitutes uncertainty in systemic lupus erythematosus and rheumatoid arthritis? Psychol Health. 2013;28(2):171-188.

45. Cleanthous S, Isenberg DA, Newman SP, Cano SJ. Patient Uncertainty Questionnaire-Rheumatology (PUQ-R): development and validation of a new patient-reported outcome instrument for systemic lupus erythematosus (SLE) and rheumatoid arthritis (RA) in a mixed methods study. Health Qual Life Outcomes. 2016;14:33.

46. Puechal X, Pagnoux C, Perrodeau E, et al. Long-term outcomes among participants in the WEGENT trial of remission-maintenance therapy for granulomatosis with polyangiitis (Wegener's) or microscopic polyangiitis. Arthritis Rheumatol. 2016;68(3):690-701. 
47. Wild D, Grove A, Martin M, et al; ISPOR Task Force for Translation and Cultural Adaptation. Principles of good practice for the translation and cultural adaptation process for patient-reported outcomes (PRO) measures: report of the ISPOR task force for translation and cultural adaptation. Value Health. 2005;8(2):94-104.

48. Ware JE Jr, Sherbourne CD. The MOS 36-item short-form health survey (SF-36). I. conceptual framework and item selection. Med Care. 1992;30(6):473-483.
49. Robson JC, Milman N, Tomasson G, et al. Exploration, development, and validation of patient-reported outcomes in antineutrophil cytoplasmic antibody-associated vasculitis using the OMERACT process. J Rheumatol. 2015;42(11):2204-2209. 


\section{Supplementary materials}

Table SI Codebook descriptions of individual themes. Collaborative codebook by core qualitative group using consensus methods

\begin{tabular}{|c|c|c|}
\hline Domain & $\begin{array}{l}\text { Individual themes of } \\
\text { interest }\end{array}$ & Description of code \\
\hline \multirow[t]{4}{*}{$\begin{array}{l}\text { I. General health } \\
\text { perceptions }\end{array}$} & $\begin{array}{l}\text { a. General sense of self and } \\
\text { wellness }\end{array}$ & $\begin{array}{l}\text { Feeling unwell/under par in a nonspecific or specific sense. Feeling less than normal. } \\
\text { Perception of self, for example, related to external appearance }\end{array}$ \\
\hline & $\begin{array}{l}\text { b. Lack of confidence in one's } \\
\text { body }\end{array}$ & $\begin{array}{l}\text { General feeling that their body could "let them down" - puts little trust in their body. Feels } \\
\text { vulnerable or dependent on medical personnel. For example, risk of falling; or sudden onset } \\
\text { of symptoms when away from help }\end{array}$ \\
\hline & c. Poor response to treatment & $\begin{array}{l}\text { Prescribed treatment ineffective (or giving only temporary relief) in general or for particular } \\
\text { symptoms. Adverse effects }\end{array}$ \\
\hline & $\begin{array}{l}\text { d. Vulnerability to infection or } \\
\text { secondary illness }\end{array}$ & $\begin{array}{l}\text { A perception that one is more vulnerable to acquiring infection and is affected for longer } \\
\text { by infections, for example, colds or secondary conditions such as cancers, diabetes, } \\
\text { hypertension, and so on }\end{array}$ \\
\hline \multirow[t]{12}{*}{$\begin{array}{l}\text { 2. Impact on } \\
\text { function }\end{array}$} & a. Level of physical function & $\begin{array}{l}\text { Cannot do same activities, or same activities to desired level - including sports/interests } \\
\text { - because of symptoms of vasculitis. A general slowness. Also include discussions of one's } \\
\text { ability to exercise and perform to the desired levels }\end{array}$ \\
\hline & b. Personal mobility & $\begin{array}{l}\text { Personal mobility problems - relating to physical capabilities, not specific to any activity or } \\
\text { task. Plus walking locally, for example, to shops or around neighborhood, descriptions of } \\
\text { being housebound. Does not include transportation }\end{array}$ \\
\hline & c. Scope for travel & $\begin{array}{l}\text { Perceived restrictions on traveling away from home because of potential need for informed } \\
\text { medical care, or risks due to reduced immunity - especially as cannot receive a live } \\
\text { vaccination }\end{array}$ \\
\hline & d. Household tasks & $\begin{array}{l}\text { Work, housework, gardening (yard work). Difficulty with carrying out "normal" everyday } \\
\text { tasks required to keep home environment in order. Maintenance, cleaning or tidying around } \\
\text { the house, garden/yard, or work - if that occupies most days }\end{array}$ \\
\hline & $\begin{array}{l}\text { e. Treatment consumes time/ } \\
\text { focus }\end{array}$ & $\begin{array}{l}\text { Effect on time management, for example, sticking to a routine for taking treatment. Lots of } \\
\text { time taken up with thinking about, or actively engaged with, treatment or monitoring of the } \\
\text { condition. Dependent on medicine/medical personnel }\end{array}$ \\
\hline & f. Adaptation & $\begin{array}{l}\text { Need to do things differently, because of effects of } \mathrm{AAV} \text {, in order to accomplish tasks. } \\
\text { Requires walking aids/supports or other devices (eg, hearing aids), to facilitate ADL }\end{array}$ \\
\hline & g. Hobbies and interests & $\begin{array}{l}\text { Impact on (loss of) hobbies/interests (not necessarily social) due to AAV. Could include } \\
\text { range of things like gardening, playing an instrument, amateur dramatics, dancing, and stamp } \\
\text { collecting. Might also include activities/interests involving technology: computer, camera, and } \\
\text { so on }\end{array}$ \\
\hline & h. Use of everyday transport & Issues relating to the ability to get around in vehicles - cars, trains, busses, and so on \\
\hline & i. Eating and drinking & $\begin{array}{l}\text { Finds it hard to eat: difficulties swallowing, fills up quickly. Difficulties with certain foods - } \\
\text { having to be careful with what they eat. Physical difficulty of getting food/drink to mouth. } \\
\text { Restriction in alcohol }\end{array}$ \\
\hline & j. Everyday technology & $\begin{array}{l}\text { Problems with using telephone, television, and so on - chiefly because of sensory problems } \\
\text { (sight/hearing) }\end{array}$ \\
\hline & k. Washing self & Difficulty with washing (all over) - mainly because of hand arm function \\
\hline & I. Dressing and undressing & $\begin{array}{l}\text { Difficulty with putting on particular clothes avoids some or needs help because of effect of } \\
\text { AAV }\end{array}$ \\
\hline \multirow[t]{3}{*}{ 3. Psychological } & $\begin{array}{l}\text { a. Uncertainty/concerns about } \\
\text { future }\end{array}$ & $\begin{array}{l}\text { Concern about what might happen to self or dependents if the condition (or ability to cope) } \\
\text { worsens including flares or shortened life/death. Difficulties or changes in relation to future } \\
\text { plans }\end{array}$ \\
\hline & b. Fear, anxiety, stress & $\begin{array}{l}\text { Easily or acutely becomes fearful or anxious; or has generalized feeling of anxiety: low } \\
\text { threshold (since AAV). Cannot cope with any extra stress - sense that they have no spare } \\
\text { capacity for dealing with stresses in life. Generalized feeling of "being a worrier" - worries } \\
\text { creep into most situations or thoughts - implies this is not normal for them (i.e., compared } \\
\text { to past or compared with how they have tended to think of themselves in the past) }\end{array}$ \\
\hline & c. AAV dominates & $\begin{array}{l}\text { Concerns or uncertainties are AAV or related symptoms serving as a barrier to getting on } \\
\text { with, or enjoying, life. Feeling as though life has been put on hold. AAV dominates thoughts. } \\
\text { A feeling of loss of control over one's own life - due to unpredictability of AAV - and its } \\
\text { severity and/or demands of treatment }\end{array}$ \\
\hline
\end{tabular}


Table SI (Continued)

\begin{tabular}{ll}
\hline Domain & $\begin{array}{l}\text { Individual themes of } \\
\text { interest }\end{array}$ \\
\hline d. Self-efficacy \\
e. Information and knowledge
\end{tabular}

Description of code

Attitude to disease. Feeling that life is a struggle - weighed down [by symptoms \pm low energy] but battling on against it OR conversely having a strong sense of self-efficacy

Descriptions of the presence or absence of information about vasculitis (what it is like, prognosis, treatments). This node assumes that the person knows they have vasculitis. Any content speaking more specifically to uncertainty/fear about the future should be coded at uncertainty

f. Support Descriptions of the person's perceived level of support - could relate to social relationships, a relationship with god/religion

g. Depression low mood

Aware of overt depression or perceived difficulty with feeling positive - constant or intermittent (but there in the background). Constant concerns about/coping with AAV removes fun and enjoyment from everyday life. Life has little purpose. Realities of living with/ concerns about/coping with AAV can affect fun and enjoyment from everyday life

h. Anger and irritation

4. Social perceptions

5. Social contact

6. Social role

a. Visibility of condition or side effects

b. Empathy and emotional connections

c. Source of other people's worry

a. Impact on social life

b. Social activities and participation

c. Adaptations to facilitate social life

d. Quality of communication

e. Sex and intimate relationships

a. Occupation or finances

b. Family and family planning

c. Dependency on others

d. Role identity and status

7. Symptoms a. Fatigue

b. Cognition and poor concentration

c. Issues related to body weight
Either due to frustration with disease or its treatment or direct effects of medication, for example, steroids

Feeling self-conscious or embarrassed about a sign/symptom of the condition or treatment obvious to other people

Perception that others (partner, family, friends) do or do not understand (how bad/ill/tired they feel). Can be coupled with reluctance to explain too much detail to others (thereby compounding the problem) or thinking that others do not believe them. May socialize more with others who have vasculitis - who understand

Perception that friends or family are anxious on their behalf - or are worried that they might become "a responsibility"/burden. Or might be contagious

Content relating to less energy for socializing, reduced social contact in person, improved social relationships, and social isolation (vulnerability, loss of confidence in social situations)

Unable to engage in social activities that the person wants to or was doing, before the illness struck, for example, sports and community participation including organized religion

AAV-related difficulties (eg, mobility problems/sensory impairment/fatigue) mean that social occasions require pacing or special planning

Impaired hearing/voice problems make communications difficult

Difficulties within relationships and with sex either because of AAV or its treatments

Worry concerned with their ability to do/or get back to doing, their job ("pull their weight"); worries about losing their job - because of effects of AAV on their ability to do their specific type of work, or any kind of work ("hold down a job"). Might include financial worries - if they were unable to continue in work (or to the same level). Loss of income - perhaps additional costs incurred, for example, house or transport adaptations, because of AAV. Could also include unpaid work

Worry about the effect that their AAV is having on their family: changing roles (their increased dependency); how family will manage if their work is affected (reduced/lost) or if they die. Feeling like a burden on their family. Effects on decisions about family size. Increasing stress and conflict within family

Needs help from others/partner to do certain tasks/go outside the home (may be contrasted with former role where others were more dependent on them)

Unable to be helpful/useful to others (as in the past) - associated with a sense of letting others down as it relates to significant others, family, or work associates. Change in status at work or in society

Fatigue, exhaustion, or energy drain, which can be intermittent, sudden, or persistent/ constant. Has "normal" level of energy some (hours or days) of the time, then suddenly overcome with fatigue/tiredness/weakness. Or persistent lack of energy, fatigue/tiredness/ weakness over many days, weeks, or months

Difficulties with focusing on a topic for any length of time. Generally feels distracted or thoughts "drift off" "in a fog." Trouble making decisions and understanding others or situations

Weight loss, gain, or distribution, causing concern - could be secondary to lost appetite or steroids

(Continued) 
Table SI (Continued)

\begin{tabular}{|c|c|c|}
\hline Domain & $\begin{array}{l}\text { Individual themes of } \\
\text { interest }\end{array}$ & Description of code \\
\hline & d. Sleep symptoms & $\begin{array}{l}\text { Difficulty getting to sleep, staying asleep, getting enough sleep. For whatever reason (including } \\
\text { psychological or physical discomfort). Difficulties with sleeping - either getting off to sleep, } \\
\text { or persistent or early waking - aggravating tiredness - for whatever reason (including } \\
\text { psychological or physical discomfort) }\end{array}$ \\
\hline & e. Temperature instability & $\begin{array}{l}\text { Sweating, shivering, including night sweats: excessive sweating at night - often while asleep - } \\
\text { for no good reason }\end{array}$ \\
\hline & f. Skin and nail problems & $\begin{array}{l}\text { Abnormal rash/marks/blotches/lumps/ulcers, affecting the skin, including signs of bleeding } \\
\text { into skin (including under nails). Added swelling of the skin and hair changes and mucous } \\
\text { membranes and Raynaud's syndrome }\end{array}$ \\
\hline & $\begin{array}{l}\text { g. Earache and hearing } \\
\text { difficulties }\end{array}$ & $\begin{array}{l}\text { Ear infections/sense of blocked ears/impaired hearing/need for hearing aid/painful ears } \\
\text { (internally)/feeling of pressure }\end{array}$ \\
\hline & h. Upper respiratory tract & $\begin{array}{l}\text { Constant feeling of nose or sinuses being blocked, congested, pressured, or running. Bleeding } \\
\text { - in quantity - from the nose, on more than one occasion. Sore throat or problems with } \\
\text { voice. Sinus infections or repeated need for treatment of some kind }\end{array}$ \\
\hline & $\begin{array}{l}\text { i. Eye symptoms and affected } \\
\text { sight }\end{array}$ & $\begin{array}{l}\text { Eye pain or irritation. Impaired or lost sight. Bleeding into eye. Cataracts. Threat/fear of losing } \\
\text { sight. Can also include watery, itchy, or dry eyes }\end{array}$ \\
\hline & j. Cardiorespiratory symptoms & $\begin{array}{l}\text { Shortness of breath/sense that breathing is labored/pain associated with breathing. Wheezing } \\
\text { or coughing. Coughing up blood. Chest pains }\end{array}$ \\
\hline & k. Gastrointestinal symptoms & Diarrhea, vomiting, nausea, bloating \\
\hline & I. Muscle symptoms & $\begin{array}{l}\text { Pain perceived as coming from muscle(s) related or unrelated to activities. Including cramps } \\
\text { including aches or pains in lower or upper back. Perceived muscle weakness or tiredness and } \\
\text { less ability to control specific muscle actions. If related to lower limbs may provoke falls }\end{array}$ \\
\hline & $\begin{array}{l}\text { m. Numbness and nerve } \\
\text { symptoms }\end{array}$ & Hypersensitivity, burning pains, or numbness along the path of a nerve \\
\hline & n. Joint symptoms & $\begin{array}{l}\text { Ache/pain, stiffness, swelling (of joints), range of movement, increased warmth perceived as } \\
\text { coming from, or in, joints - one joint or many. When at rest or following activities }\end{array}$ \\
\hline & o. Kidney and urinary tract & $\begin{array}{l}\text { Passing blood in urine or frequency or dysuria (pain or difficulty passing water) and kidney } \\
\text { problems }\end{array}$ \\
\hline & p. Appetite & $\begin{array}{l}\text { Loss of appetite. No interest in food or finds it hard to eat: difficulties swallowing, fills up } \\
\text { quickly. (new) Difficulties with certain foods - having to be careful with what they eat }\end{array}$ \\
\hline & q. Sense of taste & References to inability to taste food \\
\hline & r. Feeling unsteady or faint & $\begin{array}{l}\text { Has difficulty maintaining balance when either standing on one spot for any length of time, } \\
\text { or after initially standing up. Or gait affected. Possibly associated with sense of dizziness or } \\
\text { lightheadedness. Also include descriptions of feeling faint or fainting }\end{array}$ \\
\hline & s. Pain & $\begin{array}{l}\text { Pain in arms and hands, pain in feet and legs: low-grade aching through to severe. Intermittent } \\
\text { or persistent/constant. Could relate to muscles, joints, or nerves, and should be double } \\
\text { coded as appropriate. Any mention of pain in the face, upper sinuses, or head. Generalized } \\
\text { pain without specified cause or location }\end{array}$ \\
\hline
\end{tabular}

Abbreviations: AAV, antineutrophil cytoplasmic antibody-associated vasculitis; ADL, activities of daily life.

Box SI Translatability of the questionnaire

- The translatability of the questionnaire refers to whether items can be meaningfully translated into other languages in the future. ${ }^{50}$

- First, a concept elaboration document is produced, which clarifies any ambiguities or nuances within the candidate items and instructions.

- For each item and instruction, concepts and wording are then checked to ensure equivalence between the original and target language, and whether they remain linguistically and culturally appropriate. A sample of different types of languages is tested.

- Arabic (Egypt), Finnish (Finland), German (Germany), Greek (Greece), Russian (Russia), Spanish (Argentina), and Xhosa (South Africa) were the languages tested in this study.

- The questionnaire items were then refined to enable better cultural and linguistic equivalence across future translations, and thereby to improve the measure's performance when used in international studies.

- A translatability assessment does not go as far as conducting full-scale translation/back-translation process, with testing for validity in another language(s). This is for the future (once the number of questionnaire items has been finalized) and would require a full study for each language. However, the translatability assessment that was undertaken should ensure that future translations are more straightforward and will better facilitate equivalence. 


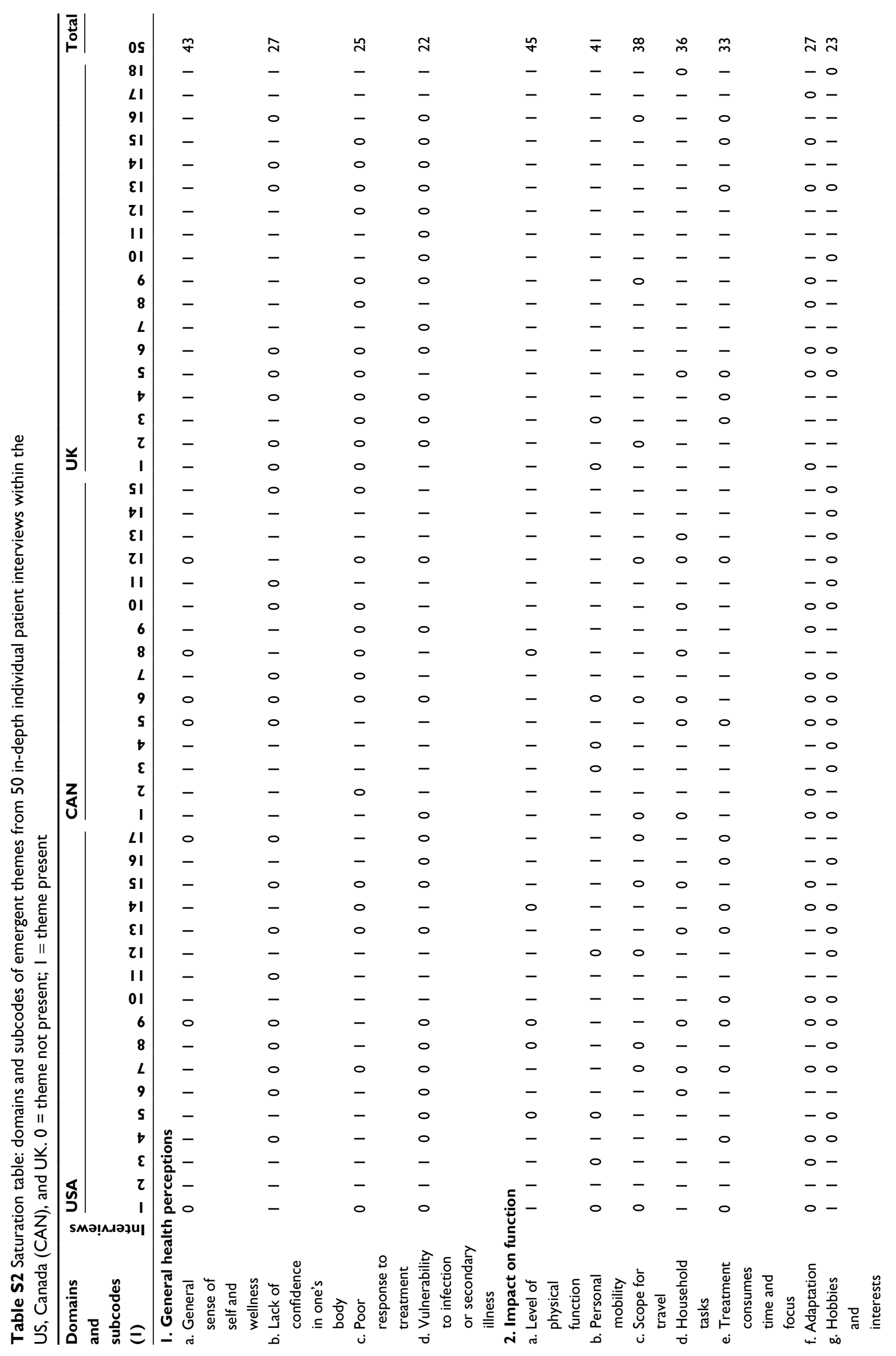




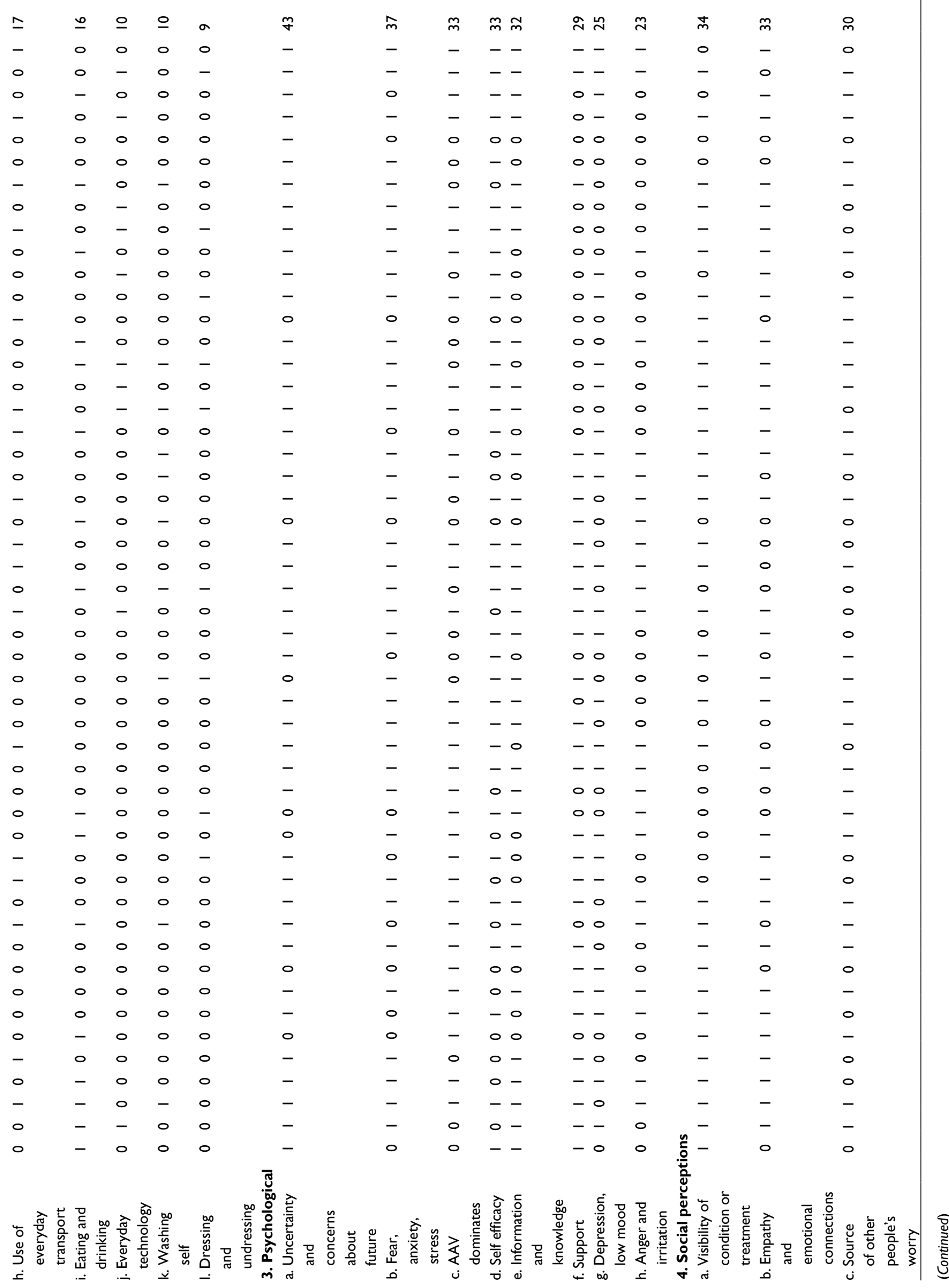




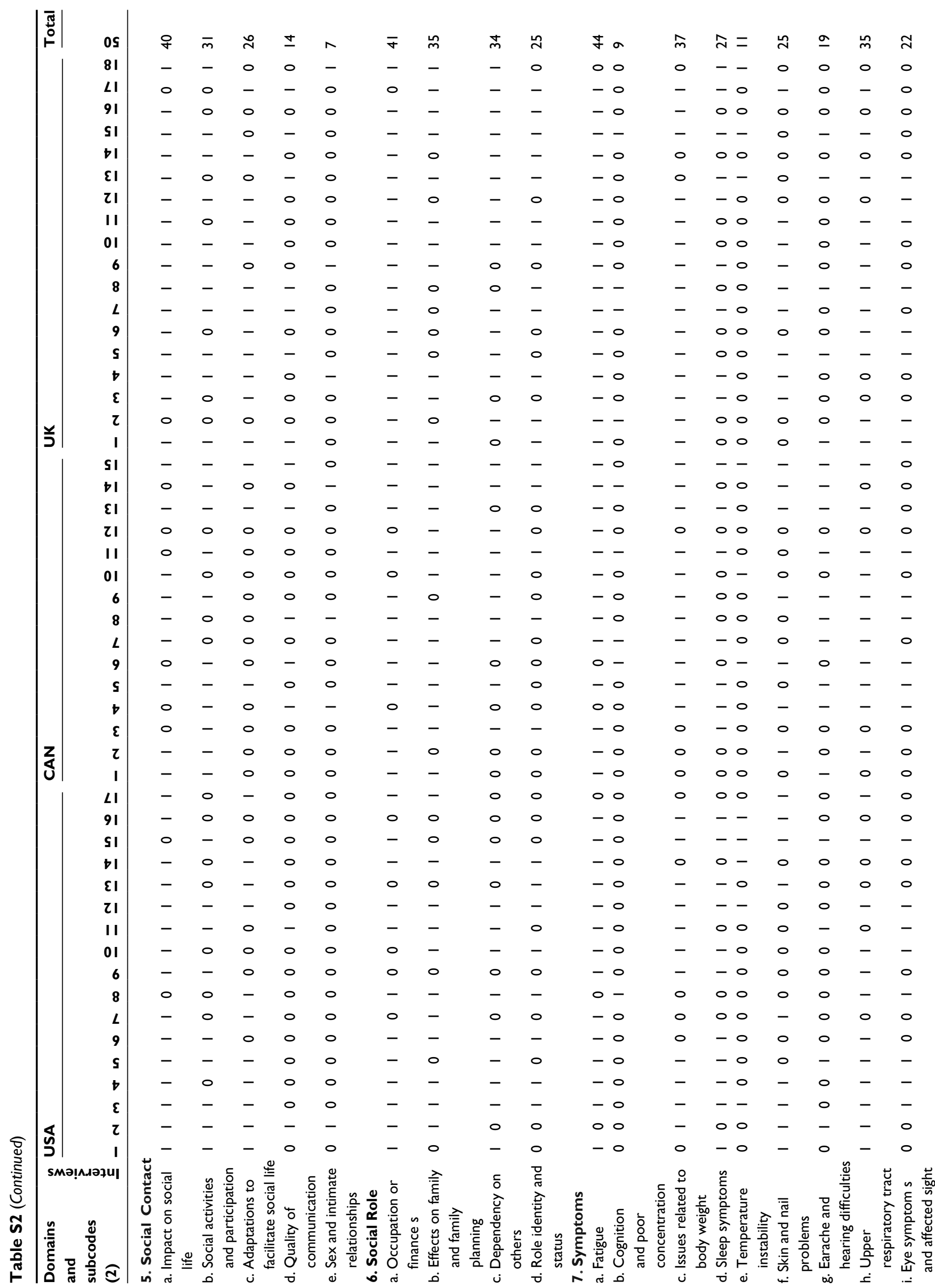




\begin{tabular}{|c|c|c|c|c|c|c|c|c|c|c|}
\hline$\stackrel{\infty}{m}$ & $\underline{\infty}$ & $\underline{0}$ & $\simeq$ & $\bar{m} \underline{m}$ & $\pm m$ & $\underline{m}$ & + & $\tilde{\sim}$ & $\underline{a}$ & $\leq a$ \\
\hline- & - & - & - & -0 & -0 & 0 & 0. & - & 0 & 00 \\
\hline- & - & - & 0 & $0-$ & 00 & - & 0 & 0 & 0 & -0 \\
\hline- & 0 & 0 & - & 00 & -0 & 0 & 0. & - & 0 & 00 \\
\hline 0 & - & - & 0 & -- & 00 & 0 & 0. & - & - & $0-$ \\
\hline- & 0 & 0 & 0 & 00 & 00 & 0 & 0 & 0 & 0 & 00 \\
\hline 0 & 0 & 0 & 0 & -- & 00 & 0 & 0. & - & - & $0-$ \\
\hline 0 & - & - & 0 & $0-$ & -0 & - & 0 & 0 & 0 & 00 \\
\hline 0 & 0 & - & 0 & -- & -0 & - & 0 & 0 & 0 & 00 \\
\hline- & - & 0 & 0 & -0 & 00 & 0 & 0. & - & - & 00 \\
\hline- & 0 & 0 & 0 & -0 & -0 & 0 & 0 & 0 & 0 & 00 \\
\hline- & - & 0 & 0 & -- & 00 & 0 & 0 & 0 & 0 & -0 \\
\hline- & - & - & 0 & -0 & 00 & - & 0. & - & 0 & 00 \\
\hline- & 0 & 0 & 0 & -0 & 00 & 0 & 0 & - & - & 00 \\
\hline- & - & - & 0 & -0 & 00 & 0 & 0 & 0 & - & -0 \\
\hline- & 0 & 0 & - & 00 & -0 & - & 0. & - & - & 00 \\
\hline 0 & - & 0 & 0 & 00 & 00 & 0 & 0 & - & - & 00 \\
\hline- & - & 0 & 0 & 00 & 00 & 0 & 0 & - & - & 00 \\
\hline- & 0 & 0 & 0 & -0 & -0 & - & 0 & 0 & 0 & 00 \\
\hline- & - & 0 & 0 & -0 & -0 & - & - & - & - & -0 \\
\hline- & 0 & - & - & -0 & -0 & - & 0 & 0 & 0 & 00 \\
\hline- & 0 & 0 & 0 & -0 & 00 & 0 & 0 & - & 0 & 00 \\
\hline- & 0 & - & - & 00 & 00 & 0 & 0 & 0 & 0 & 00 \\
\hline 0 & - & 0 & 0 & -0 & 00 & 0 & - & 0 & 0 & 00 \\
\hline- & 0 & 0 & - & -- & -0 & 0 & 0 & - & 0 & -0 \\
\hline- & 0 & 0 & 0 & -0 & 00 & - & - & - & - & -0 \\
\hline- & 0 & 0 & 0 & 00 & 00 & - & 0 & 0 & 0 & -0 \\
\hline- & - & 0 & 0 & 00 & 00 & 0 & 0 & 0 & 0 & -- \\
\hline- & 0 & 0 & 0 & -- & 00 & 0 & 0 & 0 & 0 & -0 \\
\hline 0 & 0 & - & 0 & -0 & 00 & 0 & 0 & 0 & - & -0 \\
\hline- & 0 & 0 & 0 & -0 & 00 & 0 & 0 & - & - & 00 \\
\hline- & 0 & 0 & 0 & 00 & 00 & 0 & 0 & 0 & 0 & 00 \\
\hline- & 0 & 0 & 0 & -0 & 00 & 0 & 0 & 0 & 0 & 00 \\
\hline- & 0 & 0 & 0 & -0 & 00 & 0 & 0 & 0 & 0 & $0-$ \\
\hline- & 0 & 0 & - & -0 & 00 & 0 & 0 & - & - & $0-$ \\
\hline- & 0 & - & - & -- & -- & 0 & 0 & - & - & 00 \\
\hline 0 & 0 & 0 & 0 & -- & 00 & 0 & 0 & 0 & 0 & 00 \\
\hline- & 0 & 0 & 0 & -- & 00 & 0 & 0 & 0 & 0 & -- \\
\hline 0 & 0 & 0 & - & 00 & -0 & 0 & 0 & 0 & 0 & $0-$ \\
\hline- & - & - & 0 & 00 & 00 & - & 0 & 0 & 0 & 00 \\
\hline 0 & 0 & - & - & 00 & 00 & - & 0 & - & - & 00 \\
\hline- & - & 0 & 0 & -0 & 00 & 0 & 0 & - & - & -- \\
\hline- & - & 0 & 0 & -0 & -0 & 0 & 0 & - & 0 & -0 \\
\hline 0 & - & 0 & 0 & -0 & 00 & 0 & 0 & - & 0 & 00 \\
\hline- & 0 & 0 & 0 & -- & 00 & 0 & 0 & 0 & - & $0-$ \\
\hline- & 0 & 0 & 0 & 00 & 00 & 0 & 0 & 0 & 0 & -0 \\
\hline 0 & 0 & 0 & 0 & 00 & 00 & 0 & 0 & 0 & 0 & -0 \\
\hline- & 0 & - & - & 00 & 00 & 0 & 0 & - & - & 00 \\
\hline- & - & - & 0 & -- & $0-$ & - & 0 & 0 & - & -0 \\
\hline- & 0 & - & - & 00 & -- & 0 & - & - & 0 & -0 \\
\hline- & 0 & & 0 & 00 & 00 & 0 & & 0 & 0 & 00 \\
\hline 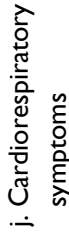 & 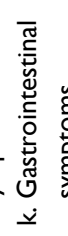 & 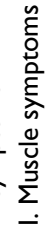 & 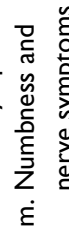 & 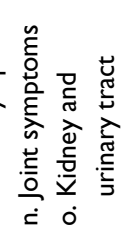 & 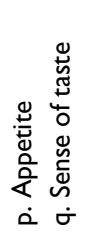 & 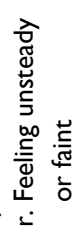 & $\frac{\pi}{d \sigma}$ & 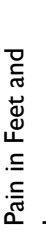 & 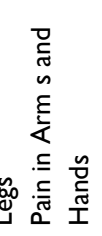 & 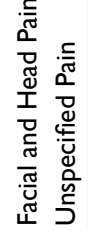 \\
\hline
\end{tabular}

\section{Reference}

1. Conway K, Patrick DL, Gauchon T, Acquadro C. Enhancing crosscultural appropriateness for newly developed patient-reported outcome (PRO) instruments: the use of translatability assessment. In. Patient Reported Outcomes Newsl. 2010;44:9-12. 


\section{Publish your work in this journal}

Patient Related Outcome Measures is an international, peer-reviewed, open access journal focusing on treatment outcomes specifically relevant to patients. All aspects of patient care are addressed within the journal and practitioners from all disciplines are invited to submit their work as well as healthcare researchers and patient support groups.
The journal is included in PubMed. The manuscript management system is completely online and includes a very quick and fair peer-review system. Visit http://www.dovepress.com/testimonials.php to read real quotes from published authors. 